\title{
Private Equity Investment and Performance of Cross-border mergers and acquisitions
}

\author{
Yuling Zheng ${ }^{\mathrm{a},{ }^{*},}$ Jiewu $\mathrm{Hu}^{\mathrm{b}}$ \\ Beijing Jiaotong University, Haidian District, Beijing, China \\ a.17120680@bjtu.edu.cn, b. jwhu@bjtu.edu.cn \\ * Corresponding author
}

\begin{abstract}
Keywords: Private equity investment, Cross-border M\&A, Short-term performance, Long-term performance
\end{abstract}

\begin{abstract}
This paper studies the role of private equity investment in cross-border mergers and acquisitions of small and medium-sized listed companies in China. The results show that the acquirers with private equity participation can achieve better short-term performance, but the impact on long-term performance is not significant. The findings of this paper provide a good enlightenment for Chinese listed companies to carry out cross-border mergers and acquisitions in the future.
\end{abstract}

\section{Introduction}

According to PWC’s “2016 Review and 2017 Outlook for Private Equity and Venture Capital Funds in China”, released on 23 February 2017, the Chinese market performed strongly in 2016, hitting records in both raising and investing compared with 2015. Among them, private equity-led mergers and acquisitions set another record in 2016, with volume up 66\% to $\$ 222.9$ billion. Cross-border mergers and acquisitions are not uncommon in private equity deals. The completion of mergers and acquisitions is the enterprise's basic prerequisites to take resources, learn experience and create value. Therefore, it is theoretical and practical to discuss the factors that affect the success or failure of overseas mergers and acquisitions of Chinese enterprises.

\section{Literature Review and Research Hypothesis}

In academic circles, there are many literatures about cross-border mergers and acquisitions (M\&As) and private equity investment (PE). One of the focuses of these literatures is to discuss the factors that affect the performance of cross-border M\&As and the impact of PE investment on the performance of enterprises from different perspectives. For example, Xie Liu and Yuanxu Li (2016) argue that formal institutional distance may have a significant negative impact on cross-border M\&A performance, geographical distance may enhance cross-border M\&A performance, and general international experience may have a negative impact on cross-border M\&A performance. ${ }^{[1]}$ There are a small number of literature to study the performance of M\&A from the perspective of the target company. Regarding the research of private equity investment, Yuanyuan Liu, Huang Zhuo and Xiaofeng He (2011) make an empirical study on the relationship between private equity investment and corporate profitability, and the results show that private equity investment can significantly improve corporate profitability and profitability. ${ }^{[2]}$

There are also some documents that link private equity investment and mergers and acquisitions. Faqin Lan et al (2017) found that the short-term market excess return and long-term holding excess return of listed companies with $\mathrm{PE}$ investment background are significantly higher than those without PE investment background. ${ }^{[3]}$

However, there are few studies on the relationship between private equity and cross-border mergers and acquisitions, From the perspective of the acquirer's background, These paper explores whether there are significant differences in the long-term and short-term performance between the acquirers with PE background and those without PE background. 
In the practice of investment in China, as that line between VC and PE become blurred, the definition of private equity investment institution in this paper is broad, including PE and VC. The information is mainly obtained from the "basic information of the counterparty of $M \& A$ " in the report of $\mathrm{M} \& \mathrm{~A}$, which includes the information of the establishment time and business scope of the shareholder of the enterprise, and if the shareholder's business scope includes equity investment and venture investment, the shareholder is deemed to be a private equity investment institution.

Jain \& Kini (1995) first pointed out that PE will strictly screen and supervise the invested enterprises, and directly participate in corporate governance. At the same time, PE also found that the quality of supervision is highly positively correlated with the operating performance after listing. ${ }^{[4]}$ Jiujin $\mathrm{Li}$ et al. (2015) studied the impact of private equity investment on the value of invested enterprises from the perspective of private equity investment characteristics. The results show that the value of enterprises with private equity participation is generally higher than that of enterprises without private equity participation. ${ }^{[5]}$ Mark Humphery-Jenner et al. (2017) show that private equity ownership ("PE backing") of the acquirer is a signal of deal quality in cross-border takeovers. And they document that the market correctly anticipates that operating performance of PE-backed acquirers increases as a result of cross-border mergers and acquisitions (M\&A). ${ }^{[6]}$ Therefore, this paper proposes the following two hypotheses:

H1: PE-backing improves the short-term performance of cross-border M\&A of Chinese listed companies

H2: PE-backing improves the long-term performance of cross-border M\&A of Chinese listed companies

\section{Research design}

\subsection{Sample Selection and Data Source}

This paper selects the cross-border M\&A transactions from 2010 to 2017 of Chinese SME listed companies as the sample data, Sample screening criteria are as follows: the purchaser is a listed company on the China Small and Medium-sized Board, the subject company is an enterprise whose place of registration and actual place of business are both abroad, excluding related party transactions, excluding transactions without obtaining control rights, excluding samples of financial listed companies, excluding samples of missing data of key variables. According to the above criteria, 89 samples of cross-border M\&A are obtained. In addition, the stock price and the stock index of the corresponding market used in this paper are from WIND database, and the stock price before and after M\&A is based on the daily data.

\subsection{Variable selection}

Table 1 The information about variables

\begin{tabular}{|l|l|l|}
\hline Variable type & Variable Name & Calculation method \\
\hline \multirow{4}{*}{$\begin{array}{l}\text { Dependent } \\
\text { variable }\end{array}$} & $\begin{array}{l}\text { Short-term performance } \\
\text { CAR }(-\mathrm{t}, \mathrm{t})\end{array}$ & $\begin{array}{l}\text { Accumulated excess return on the day before and } \\
\text { after the announcement date of the Acquirer }\end{array}$ \\
\cline { 2 - 3 } & $\begin{array}{l}\text { Long-term performance } \\
\Delta \text { Opf }\left(\mathrm{t}, \mathrm{t}_{\mathrm{i}}\right)\end{array}$ & $\begin{array}{l}\text { EPS's growth rate after M\&A relative to the year } \\
\text { before M\&A }\end{array}$ \\
\hline \multirow{4}{*}{$\begin{array}{l}\text { Independent } \\
\text { variable }\end{array}$} & PE_backed & $\begin{array}{l}1 \text { if the acquirer has PE institutional background and } \\
\text { 0 otherwise }\end{array}$ \\
\hline \multirow{5}{*}{ Control variable } & The number of PE institutions \\
\cline { 2 - 3 } & SE_number & $\begin{array}{l}\text { Natural logarithm of total assets of acquirer in the } \\
\text { year prior to M\&A }\end{array}$ \\
\cline { 2 - 3 } & Debt & Total liabilities/total assets \\
\cline { 2 - 3 } & Growth & TobinQ in the year prior to M\&A \\
\cline { 2 - 3 } & Year & \\
\cline { 2 - 3 } & Industry & \\
\hline
\end{tabular}

\subsection{Model}

Build the following model: 
CAR $(-1,1)=\alpha_{1}+\beta_{1}$ PE_backed $+\beta_{2}$ PE_number $+\beta_{3}$ Size $+\beta_{4}$ Debt $+\beta_{5}$ Growth + Year

+ Industry+ $\varepsilon_{1}$

CAR $(-2,2)=\alpha_{2}+\beta_{1}$ PE_backed $+\beta_{2}$ PE_number $+\beta_{3}$ Size $+\beta_{4}$ Debt $+\beta_{5}$ Growth + Year

+ Industry $+\varepsilon_{2}$

$\Delta \mathrm{Opf}(\mathrm{t}, \mathrm{t} 1)=\alpha_{3}+\beta_{1} \mathrm{PE} \_$backed $+\beta_{2} \mathrm{PE} \_$number $+\beta_{3}$ Size $+\beta_{4}$ Debt $+\beta_{5}$ Growth + Year

+ Industry $+\varepsilon_{3}$

$\Delta \mathrm{Opf}(\mathrm{t}, \mathrm{t} 2)=\alpha_{4}+\beta_{1} \mathrm{PE} \_$backed $+\beta_{2} \mathrm{PE} \_$number $+\beta_{3}$ Size $+\beta_{4}$ Debt $+\beta_{5}$ Growth + Year

+ Industry $+\varepsilon_{4}$

\section{Analysis of empirical results}

\subsection{Descriptive statistics}

Table 2 the results of descriptive statistics

\begin{tabular}{|c|c|c|c|c|c|c|c|c|}
\hline & Number & Mean & Std. & Min & Q1 & Q2 & Q3 & Max \\
\hline CAR $(-1,1)$ & 89 & -0.07 & 0.97 & -9.13 & -0.02 & 0.007 & 0.05 & 0.28 \\
\hline CAR $(-2,2)$ & 89 & -0.04 & 0.88 & -8.13 & -0.02 & 0.008 & 0.08 & 1.02 \\
\hline$\Delta$ Opf $(\mathrm{t}, \mathrm{t} 1)$ & 74 & -0.87 & 4.08 & -28.4 & -0.55 & -0.17 & 0.26 & 5.08 \\
\hline$\Delta$ Opf $(\mathrm{t}, \mathrm{t} 2)$ & 57 & -0.12 & 1.48 & -7.23 & -0.61 & -0.2 & 0.34 & 4.03 \\
\hline
\end{tabular}

According to the descriptive statistics, the average cumulative excess return of window period $(-1,1)$ is- 0.07 , which is the reason why the minimum value of- 9.13 lowers the overall average level. The excess cumulative return has gradually become positive from the upper quartile, indicating that the cross-border M\&A with private equity participation has a corresponding positive impact on the short-term $M \&$ A performance. This is also evidenced by the fact that the window period $(-2,2)$ is similar to the case of $(-1,1)$.

Since the 2016 and 2017 mergers and acquisitions events don't have long-term financial indicators, the corresponding missing data has been excluded, with 74 samples of

$\triangle \mathrm{Opf}\left(\mathrm{t}, \mathrm{t}_{1}\right)$ and 57 samples of $\triangle \mathrm{Opf}\left(\mathrm{t}, \mathrm{t}_{2}\right)$. The median growth rate of EPS is negative in one year and two years after M\&A, but it is positive in the first quartile, which indicates that the cross-border M\&A with PE institutions has little positive effect on the long-term performance of listed companies, and may even have negative effect, which is related to the insufficiency of integration ability after M\&A.

\subsection{Multiple regression analysis}

Table 3 The results of multiple regression

\begin{tabular}{|c|c|c|c|c|}
\hline Variables & CAR $(-1,1)$ & CAR $(-2,2)$ & $\Delta$ Opf $(\mathrm{t}, \mathrm{t} 1)$ & $\Delta$ Opf $(\mathrm{t}, \mathrm{t} 2)$ \\
\hline \multirow{2}{*}{ c cons } & $4.03^{* *}$ & $3.65^{* *}$ & $-24.74^{* * *}$ & 2.5 \\
\cline { 2 - 5 } & $(2.02)$ & $(2.02)$ & $(-2.73)$ & $(0.66)$ \\
\hline \multirow{2}{*}{ PE_backed } & $0.05^{* * *}$ & $0.09^{* *}$ & -0.26 & -0.01 \\
\cline { 2 - 5 } & $(2.7)$ & $(2.1)$ & $(-0.15)$ & $(-0.01)$ \\
\hline \multirow{2}{*}{ PE_number } & -0.08 & -0.08 & -0.55 & 0.12 \\
\cline { 2 - 5 } & $(-0.7)$ & $(-0.76)$ & $(-0.69)$ & $(0.26)$ \\
\hline \multirow{2}{*}{ Size } & $-0.38^{* *}$ & $-0.34^{* *}$ & $2.04 * * *$ & -0.26 \\
\cline { 2 - 5 } & $(-2.27)$ & $(-2.26)$ & $(2.7)$ & $(-0.83)$ \\
\hline \multirow{2}{*}{ Debt } & $1.8^{* * *}$ & $1.6^{* * *}$ & -3.18 & $(1.41)$ \\
\cline { 2 - 5 } & $(2.6)$ & $(2.67)$ & $(-1.02)$ & -0.05 \\
\hline Growth & 0.015 & 0.01 & -0.02 & $(-0.39)$ \\
\cline { 2 - 5 } & $(0.52)$ & $(0.45)$ & $(-0.17)$ & 0.06 \\
\hline R & 0.12 & 0.12 & 0.13 & 1.54 \\
\hline Vif & 1.54 & 1.54 & 1.54 & \\
\hline
\end{tabular}

The number in parenthesis is t statistic, ${ }^{* * *} \mathrm{p}<0.01,{ }^{* *} \mathrm{p}<0.05,{ }^{*} \mathrm{p}<0.1$ 
According to the results of multiple regression, PE institutions' participation in cross-border mergers and acquisitions is positively correlated with the short-term performance of listed companies. PE-backing in cross-border mergers and acquisitions can improve the short-term performance of listed companies at the level of $(-1,1)$ and $(-2,2)$, which is significant at the level of $1 \%$ and $5 \%$ respectively. This positive effect decreases over time, the result supports $\mathrm{H} 1$.

The PE-backing is negatively correlated with the performance of long-term mergers and acquisitions, but it does not pass the significant test, so the impact of the PE-backing on the long-term performance of mergers and acquisitions needs further study. So we can reject H2 .

In addition, the regression results show that the size of the company is negatively correlated with the performance of short-term mergers and acquisitions, which is significant at the level of $5 \%$. The debt ratio is positively correlated with short-term performance, which is significant at $1 \%$ level. The variance expansion factor VIF of the model is less than 2, and there is no serious problem of collinearity.

\section{Conclusions}

This paper studies the cross-border mergers and acquisitions of Chinese listed companies from 2010 to 2017. Using event study method and financial indicators method, this paper empirically studies the impact of PE-backing on the performance of cross-border mergers and acquisitions of Chinese listed companies, and draws the following conclusions:

The PE background of the acquirer improves the short-term performance of cross-border mergers and acquisitions of small and medium-sized listed companies in China. In addition, from the long-term performance point of view, PE-backing has no significant impact on the listed companies.

The main shortcoming of this paper is the research method itself, because stock market is difficult to achieve strong and efficient, so using the market response to measure the performance of mergers and acquisitions has certain limitations.

\section{References}

[1] Xie Liu, Yuanxu Li. Research on the factors influencing the performance of Chinese enterprises' cross-border mergers and acquisitions . Journal of University of Foreign Economics and Economics, vol.03, pp. 65-73,2016.

[2] Yuanyuan Liu, Zhuo Huang, Xiaofeng He. Research on IPO initial Return and Venture Capital Participation--An Empirical Study Based on China's Growth Enterprise Market. Modern Economic Science, vol.02, pp.64-70,2012.

[3] Faqin Lan, Jianwu Zhao, Fanping Wang, Rui Zhu. Private equity investment, target companies and merger performance--evidence from China's growth enterprise market. Shanghai Finance, vol.06, pp.49-57,2017.

[4] B.A. Jain, O Kini. Venture capital partition and the post-Issue operating perfor of IPO firms . Managerial and Decisions Economics, vol.06, pp. 593-606,1995.

[5] Jiujin Li, Fusheng Wang. The influence of private equity investment characteristics on the value of invested enterprises--A study based on IPO enterprise experience data from 2008 to 2012. Nankai Management Review, vol.05, pp. 151-160, 2015.

[6] M.H.Jenner, Zacharias Sautner, JO-Annsuchard. Cross-border mergers and acquisitions: the role private equity firms. Strategic Management Journal, vol.38, pp.1688-1700,2017. 